\title{
Long-Term Outcomes of Sialendoscopy in the Management of Sialolithiasis and Idiopathic Chronic Sialadenitis with Ductal Scars
}

\author{
Evren Erkul ${ }^{1}$ (1), Engin Çekin² ${ }^{2}$ Atila Güngör ${ }^{3}$ \\ ${ }^{1}$ Department of Otorhinolaryngology, University of Health Sciences, Gülhane Medical School, Sultan Abdulhamid Han Training \\ and Research Hospital, İstanbul, Turkey \\ ${ }^{2}$ Department of Otorhinolaryngology, University of Health Sciences, Sultan Abdulhamid Han Training and Research Hospital, \\ Original Investigation $>$ İstanbul, Turkey \\ ${ }^{3}$ Department of Otorhinolaryngology, Medical Park Hospital Göztepe, İstanbul, Turkey
}

\begin{abstract}
Objective: We aimed to present the long-term outcomes and sialendoscopic findings in only patients with sialolithiasis and ductal scars in idiopathic chronic recurrent sialadenitis who experienced unsuccessful results with conservative treatment and were treated with sialendoscopy.
\end{abstract}

ORCID ID of the author:

E.E. 0000-0002-0360-1309.

Cite this article as: Erkul E, Çekin E, Güngör A. Long-Term Outcomes of Sialendoscopy in the Management of Sialolithiasis and Idiopathic Chronic Sialadenitis with Ductal Scars. Turk Arch Otorhinolaryngol 2019; 57(2):75-80.

\section{Corresponding Author:}

Evren Erkul; evrenerkul@yahoo.com

Received Date: 21.03.2019

Accepted Date: 28.05.2019

DOl: 10.5152/tao.2019.4290

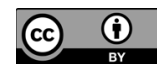

Content of this journal is licensed under a Creative Commons Attribution 4.0 International License.

Available online at www.turkarchotolaryngol.net
Methods: We retrospectively analyzed the patients with a diagnosis of only sialolithiasis and ductal scars in chronic recurrent sialadenitis who underwent sialendoscopy between January 2011 and June 2016. We collected clinical and intraoperative data including patient age, sex, date of the procedure, the involved gland, operative findings and complications. Follow-up data included whether the symptoms were resolved or recurred and whether any further procedures were performed.

Results: Of a total of 38 patients, 16 were excluded from the study due to missing clinical or follow-up
The aim of intervening with salivary gland diseases is to reveal the pathology behind them and to treat with the least invasive method. As in all otorhinolaryngological diseases, treatment approaches have focused on organ preservation methods in the recent years. In the early 1990s, the anatomy and diseases of the gland and ductal system started to be evaluated better by the first salivary gland endoscopes of Konigsberger and Katz $(1,2)$. The first sialendoscopy case series were published in 1997 by Nahlieli and in 2000 by Marchal (2). Nahlieli et al. (2) reported the first sialendoscopy results on juvenile recurrent parotitis (JRP) and radioactive iodine (RAI) sialadenitis in 2004 and 2006, respectively.

\section{Introduction}

data, and analysis was conducted on 22 patients. Twelve were diagnosed with sialolithiasis, while the remaining 10 were diagnosed with idiopathic chronic sialadenitis and had ductal scars. Stone sizes ranged from $2 \mathrm{~mm}$ to $10 \mathrm{~mm}$. Mean follow-up time was 39.5 months. The final success rate was $100 \%$. Of the 10 patients with ductal scarring, five had scar in the parotid gland duct, and five in the submandibular gland duct. The mean follow-up time of all ductal scar patients was 47.1 months. The final success rate was $70 \%$.

Conclusion: Sialendoscopy is a minimally invasive method for the diagnosis and treatment of sialolithiasis and ductal scars of the salivary glands after failure of conservative treatments in adults.

Keywords: Sialendoscopy, sialolithiasis, ductal scar, salivary gland, sialadenitis
Sialendoscopy increases the rate of organ preservation in the application of interventional treatment methods. Sialendoscopy is a minimally invasive procedure for salivary gland diseases, and its main indications are sialolithiasis, non-stone obstructive salivary gland diseases, including chronic idiopathic recurrent sialadenitis, JRP, RAI-induced sialadenitis and auto-immune sialadenitis, such as Sjögren syndrome (3-7). Sialendoscopy is often the choice of treatment when the patient does not respond to other conservative and preventive treatment approaches $(2,3)$.

Sialendoscopy helps physicians see and diagnose the pathology with direct high-quality imaging using a semi-flexible endoscopy system with high 
success rates and without exposure to contrast agents and irradiation. There are many complications after traditional salivary gland surgeries, but with sialendoscopy, the rates of serious complications and cosmetic problems such as incision scars are considerably lower $(5,6,8,9)$. The exact disappearance or reduction rate of complaints after sialendoscopy applications ranges from 80 to $90 \%$, and the success rates of sialolithiasis are higher than those of non-stone disorders $(5-7,10,11)$. There is an increasing global tendency and use of sialendoscopy in the diagnosis and treatment of obstructive salivary gland disorders.

Our study especially aimed to focus on and report the long-term outcomes of a specific group other than all patients with obstructive salivary gland disease who were treated by sialendoscopy. Consequently, we aimed to present the long-term outcomes and sialendoscopic findings in only patients with sialolithiasis and ductal scars in idiopathic chronic recurrent sialadenitis who experienced failure with conservative treatment and were treated with the sialendoscopy approach.

\section{Methods}

\section{Patients and data}

We retrospectively analyzed 38 patients with only the diagnosis of sialolithiasis and ductal scars in chronic recurrent sialadenitis who underwent sialendoscopy between January 2011 and June 2016. This study was approved by the medical ethics committee of Haydarpaşa Numune Research and Training Hospital (Approval Nr. HNEAH-KAEK 28/01/2019/KK/1) and conducted based on the principles of the Declaration of Helsinki. All procedures were performed at the Gülhane Military Medical Academy, Haydarpaşa Research and Training Hospital in İstanbul, Turkey. Informed consent forms for the sialendoscopic surgery were signed by all patients. The patients underwent one or multiple sialendoscopy procedures. Therefore, a total of 45 procedures were performed. We collected clinical and intraoperative data including patient age, sex, date of procedure, the involved gland(s), operative findings and complications. Removed stones were analyzed for data describing the number and size of the stones, removal techniques and whether the removal was successful. When stenosis was seen, we used the "Description of Salivary Duct Scar Tissue" table that was defined by Erkul and Gillespie (7). Follow-up data included any postoperative complications, whether the symptoms disappeared or recurred and whether any further procedures were performed.

The exclusion criteria were: being under the age of 18 years, presence of RAI-induced sialadenitis and auto-immune sialadenitis such as Sjögren syndrome, previous surgeries for salivary gland diseases, missing clinical data and a follow-up period of shorter than 12 months.

\section{Surgical techniques}

We used a Karl Storz (Tuttlingen, Germany) endoscope with a $1.6 \mathrm{~mm}$ outer diameter, which had an irrigation port and a $0.8 \mathrm{~mm}$ sleeve that allowed for more extensive instrumentation. Instrumentation included forceps, a balloon, basket, guidewire and laser.
Sialendoscopy was performed in our institution under either local or general anesthesia. The punctum was found by the help of a dilator over which an angiocatheter was fed, and the punctum of the affected gland was swiftly dilated under magnification using punctum dilators until the sialendoscope could be introduced. Guidewire was often used to reintroduce the sialendoscope easily during the procedure so that it would help prevent perforation.

The duct was visualized with the endoscope along its entire length to assess pathology. Strictures and stenoses were dilated by hydro-dissection, balloon catheters and baskets or directly with endoscopes, and mucus plugs were removed by irrigation and baskets. When a stone was identified, removal was first attempted using a basket, a balloon catheter to pull from behind, irrigation as a mobilization technique, or forceps. If the stone remained wedged within the duct or was too large to be removed with these techniques, it was fragmented by the laser for removal of the fragments by a basket or forceps, or a combined open surgery technique was used to remove the stone from the duct with the guidance of a sialendoscope. We used Holmium: YAG laser lithotripsy with $365 \mu \mathrm{m}$ fiber, 1 Joule (J) energy and $5 \mathrm{~Hz}$ frequency (Sphinx, CA, USA). The ducts were repaired by suturing, putting stents into the duct after the stone was removed, or a new orifice was made by marsupialization of the duct. We inserted a $26 \mathrm{G}$ pediatric angiocatheter as a stent in both parotid and submandibular ducts. All ducts were irrigated with Dexamethasone by $8 \mathrm{mg} / 2 \mathrm{ml}$ at the end of the procedure.

All patients were recommended to stay well-hydrated and massage their salivary gland postoperatively. Antibiotics (amoxicillin/clavulanic acid [875 mg/125 mg] BID) and analgesics were given to all patients for seven days.

The patients were followed-up either at the office or by telephone conversations regarding the persistent symptoms or complications of the procedure.

\section{Results}

The study initially included 38 patients of whom 16 were excluded due to missing clinical or follow-up data, and we retrospectively analyzed 22 patients. Among these 22 patients, sialolithiasis was diagnosed in 12 , and the remaining 10 patients with idiopathic chronic sialadenitis had ductal scars. Twenty-two patients underwent 24 sialendoscopy procedures in $9 \mathrm{pa}$ rotid glands and 13 submandibular glands. There were 10 (45\%)

Table 1. Demographic characteristics of patients

\begin{tabular}{l|c|c}
\hline \multirow{2}{*}{ Age (years) } & Sialolithiasis & Ductal scar \\
\hline Sex (male/female) & 34.58 & 48 \\
\hline Gland (submandibular/parotid) & $(17-63)$ & $(26-62)$ \\
\hline Follow-up (months) & $7 / 5$ & $5 / 5$ \\
\hline
\end{tabular}


female and $12(55 \%)$ male patients with ages ranging from 17 to 63 years (Table 1). Two patients underwent repeated endoscopy for recurrent symptoms. All patients underwent preoperative imaging by ultrasonography. Only four patients had computerized tomography (CT) scans.

Of the 12 sialolithiasis patients, eight had submandibular gland stones, and four had parotid gland stones (Table 2). The size of the stones ranged from $2 \mathrm{~mm}$ to $10 \mathrm{~mm}$ (Figure 1). Multiple stones were examined in three patients. Combined lithotomy technique was performed for four submandibular stones and one parotid stone. A $6 \mathrm{~mm}$ submandibular stone was initially fragmented by a laser and then removed by a basket. Eleven of the 12 patients with stones had complete symptom recovery. One patient was found to have a new stone in the $60^{\text {th }}$ month after the initial sialendoscopy, and sialendoscopy was repeated in this patient. Two of the 12 patients had ductal scars accompa- nying sialolithiasis (Table 2). The mean follow-up time was 39.5 months. The final success rate was $100 \%$.

Of the 10 patients with ductal scarring, five had a scar in the parotid gland duct and five in the submandibular gland duct. Mucus plugs were observed in all patients. The appearance and classification of the ductal scars are shown in Table 3. Six of these 10 patients had complete symptom recovery in the follow-up period. One out of the four patients who did not have complete recovery had repeated sialendoscopy procedures in the $23^{\text {rd }}$ month after the initial sialendoscopy. A new scar was observed and opened by the endoscope, and complete symptom recovery was eventually achieved. The mean follow-up time of all ductal scar patients was 47.1 months. The final success rate was $70 \%$.

All patients had temporary swelling for 3-4 hours after the surgery. We observed no serious complications. One patient had a

Table 2. Clinical findings of sialolithiasis patients

\begin{tabular}{|c|c|c|c|c|c|c|c|}
\hline $\mathbf{N}$ & Sex & Age & Gland & Side & Endoscopic Procedure & Size $(\mathrm{mm})$ & Symptom Resolution \\
\hline 1 & M & 37 & SM & RIGHT & In combination with lithotomy & $5 \mathrm{~mm}$ & COMPLETE \\
\hline 2 & $\mathrm{M}$ & 48 & $\mathrm{SM}$ & LEFT & In combination with lithotomy & $6 \mathrm{~mm}$ & $\begin{array}{c}\text { PARTIAL } \\
\text { (Complete after } \\
\text { repeated endoscopy) }\end{array}$ \\
\hline 3 & M & 27 & $\mathrm{SM}$ & LEFT & In combination with lithotomy & $5 \mathrm{~mm}$ & COMPLETE \\
\hline 4 & $\mathrm{~F}$ & 63 & $\mathrm{P}$ & LEFT & Basket & $3 \mathrm{~mm}$ & COMPLETE \\
\hline 5 & $\mathrm{M}$ & 17 & $\mathrm{SM}$ & RIGHT & Basket & $4 \mathrm{~mm}$ & COMPLETE \\
\hline 6 & $\mathrm{~F}$ & 21 & $\mathrm{SM}$ & RIGHT & Laser and basket & $6 \mathrm{~mm}$ & COMPLETE \\
\hline 7 & $\mathrm{M}$ & 26 & $\mathrm{P}$ & RIGHT & $\begin{array}{l}\text { In combination with lithotomy } \\
\text { and basket }\end{array}$ & $6 \mathrm{~mm}, 9 \mathrm{~mm}, 4 \mathrm{~mm}$ (3 stones) & COMPLETE \\
\hline 8 & $\mathrm{~F}$ & 42 & $\mathrm{P}$ & RIGHT & Basket & $4 \mathrm{~mm}, 4 \mathrm{~mm}$ (2 stones) & COMPLETE \\
\hline 9 & M & 24 & $\mathrm{SM}$ & LEFT & Basket, forceps & $2 \mathrm{~mm}, 2 \mathrm{~mm}, 2 \mathrm{~mm}$ (3 stones) & COMPLETE \\
\hline 10 & $\mathrm{~F}$ & 38 & $\mathrm{P}$ & RIGHT & Basket & $4 \mathrm{~mm}$ & COMPLETE \\
\hline 11 & M & 34 & $\mathrm{SM}$ & LEFT & Basket & $4 \mathrm{~mm}$ & COMPLETE \\
\hline 12 & $\mathrm{~F}$ & 38 & SM & RIGHT & In combination with lithotomy & $10 \mathrm{~mm}$ & COMPLETE \\
\hline
\end{tabular}

N: number; M: male; F: female; SM: submandibular; P: parotid

Table 3. Clinical and endoscopic findings of ductal scar patients

\begin{tabular}{|c|c|c|c|c|c|c|c|c|c|}
\hline $\mathbf{N}$ & Sex & Age & Gland & Side & ScarType & Scar Location & Scar Grade/Extent & Ductal Tissue Color & Symptom Resolution \\
\hline 1 & $\mathrm{~F}$ & 37 & $\mathrm{SM}$ & LEFT & Stricture & Distal & $1 / \mathrm{S} 0$ & Pale & COMPLETE \\
\hline 2 & $\mathrm{~F}$ & 62 & $\mathrm{P}$ & LEFT & Stricture & Ostium, Distal & $1 / \mathrm{S} 0$ & Erythematous & $\begin{array}{c}\text { PARTIAL } \\
\text { (Complete after } \\
\text { repeated endoscopy) }\end{array}$ \\
\hline 3 & $\mathrm{M}$ & 57 & $\mathrm{SM}$ & RIGHT & Stricture & Proximal & $1 / \mathrm{S} 0$ & Pale & COMPLETE \\
\hline 4 & $\mathrm{M}$ & 57 & $\mathrm{P}$ & RIGHT & Stricture & Distal & $1 / \mathrm{S} 0$ & Erythematous & COMPLETE \\
\hline 5 & $\mathrm{~F}$ & 58 & $\mathrm{P}$ & LEFT & Stenosis & Proximal & $2 / \mathrm{S} 2$ & Pale & COMPLETE \\
\hline 6 & $\mathrm{M}$ & 54 & $\mathrm{P}$ & RIGHT & Stricture & Distal & $1 / \mathrm{S} 0$ & Pale & PARTIAL \\
\hline 7 & $\mathrm{~F}$ & 26 & $\mathrm{P}$ & LEFT & Stenosis & Distal & $3 / \mathrm{S} 2$ & Pale & COMPLETE \\
\hline 8 & $\mathrm{~F}$ & 53 & $\mathrm{SM}$ & RIGHT & Stricture & Distal & $1 / \mathrm{S} 0$ & Erythematous & PARTIAL \\
\hline 9 & $\mathrm{M}$ & 49 & SM & LEFT & Stricture & Proximal & $1 / \mathrm{S} 0$ & Pale & PARTIAL \\
\hline 10 & $\mathrm{M}$ & 27 & SM & LEFT & Stricture & Distal & $1 / \mathrm{S} 0$ & Pink & COMPLETE \\
\hline
\end{tabular}

$\mathrm{N}$ : number; M: male; F: female; SM: submandibular; P: parotid 
prolonged temporary swelling in his parotid region, but it was resolved completely on the $7^{\text {th }}$ postoperative day. One patient who had stone removal surgery with a transoral open combination surgery with lithotomy had temporary lingual nerve paresthesia for two days after the surgery.

\section{Discussion}

Salivary gland stones are the most common cause of obstructive salivary disorders, and salivary duct scars are the second most common ones after stones. Sialendoscopy has become a common approach in the treatment of stone-related salivary obstruction and is being increasingly applied in salivary obstruction cases caused by a wide variety of non-stone disorders. Sialendoscopy is a minimally invasive approach with a low rate of complications for the diagnosis and the treatment of obstructive salivary gland diseases $(5,7,8)$. Acute sialadenitis is the only absolute contraindication for sialendoscopy. In our study, we examined the long-term follow-up and clinical data of 22 patients-in whom we identified stones and/or ductal scars during the sialendoscopy procedures-for the etiology of the stone and idiopathic chronic sialadenitis and found a rate of $85 \%$ complete recovery. Our study was one of the first sialendoscopy studies in Turkey that reported long-term results only for stones and ductal scars.

Different sizes and numbers of stones, a narrow ductal lumen, mucus plugs and strictures may be seen by diagnostic sialendoscopy in patients with obstructive sialadenitis $(5,6,12,13)$. Sialendoscopy is an effective treatment modality for those who do not respond to conservative medical treatments. This is attributed to the dilatation of strictures, the removal of the mucus plugs and the stones, and the reduction of inflammation from steroid irrigations by sialendoscopy alone or in combination with other techniques $(3,14)$. In our clinical practice, we have always performed sialendoscopy when all conservative maximal medical treatment approaches failed. We initially treated patients by hydration, compression and gland massage, and added antibiotics for the infected gland as a maximal medical treatment. We never performed sialendoscopy during acute sialadenitis.

The success rates for stone removal depend on the size, the location and the number of the stones, adherence to the duct, and the experience level of the surgeon. Gillespie et al. (15) reported a stone size of larger than $7 \mathrm{~mm}$, insufficient experience, and unavailability of lithotripsy or a laser decrease the success of sialendoscopy. Matsunobu et al. (16) retrospectively evaluated 78 sialolithiasis cases that had sialendoscopy and reported that stone size (favorably $<5 \mathrm{~mm}$ ), stone shape (favorably with smooth surface and oval-shaped) and the distance from the papilla (favorably close to the papilla) had significant relationship with success rates. In our study, the success rate was high because we had the ability to use a combination of techniques with lithotomy and a laser for both parotid and submandibular gland stones. Additionally, we believed that non-floating stones which were larger than $5 \mathrm{~mm}$ in size might need to be fragmented by a laser or removed by open surgery by the guidance of sialendoscopy, and these approaches helped increase our success rates.

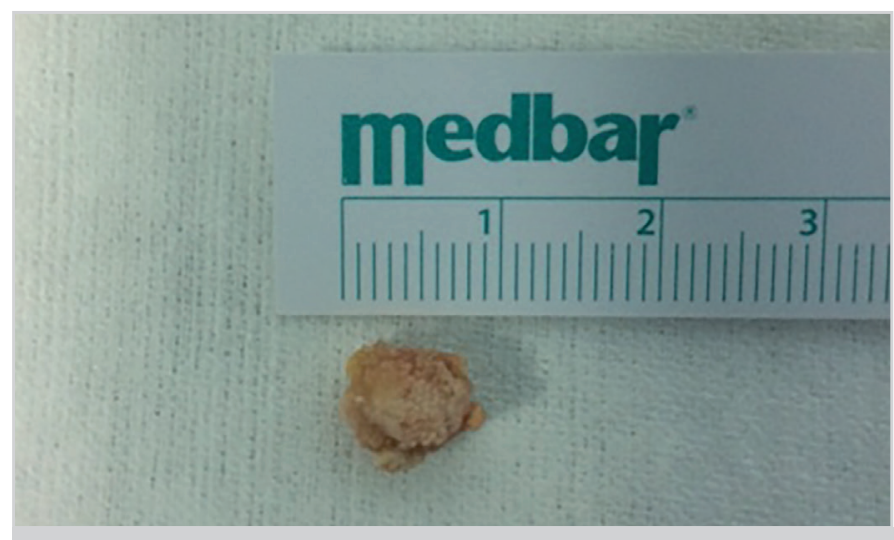

Figure 1. Complete removal of the $10 \mathrm{~mm}$ stone of the patient (Patient number 12 in Table 2)

Pace et al. (13) reported that floating stones $<9 \mathrm{~mm}$ in size may be removed with the help of a basket, and a small papillotomy procedure may be required for stones $<2 \mathrm{~mm}$. In their study, 48 (91\%) of 53 patients were asymptomatic at the end of one year. In our study, we had a 39.5-month follow-up period for stones, which was longer than the time period reported by Pace et al. Our final success rate was $100 \%$. We only needed one repeated sialendoscopy in a patient who had a recurrence after 60 months following the first sialendoscopy procedure.

Another option for stones which have a size of $5-7 \mathrm{~mm}$ is fragmenting the stones in the duct by forceps, lasers or drills. In the presence of multiple stones, techniques similar to above-mentioned ones are performed. Capaccio et al. (17) treated eight patients with parotid stones larger than $7 \mathrm{~mm}$ in the main duct or the parenchyma with an endoscopy-assisted transfacial surgical approach (McGurk technique under general anesthesia was performed in six patients, and Nahlieli technique under local anesthesia in two patients), and they failed in only one patient. They reported that this approach is an alternative method to parotidectomy, but cannot be applied in non-palpable large parotid gland stones. With the technological advancement of flexible telescopes and instruments, larger stones can be removed through the duct. Intracorporal lithotripsy may be performed with different types of lasers. XeCl excimer, Ho: YAG laser and erbium: YAG laser are frequently used.With flexible fiber ends, stones can be fragmented into small pieces. The most commonly used laser is Holmium-YAG. (10, 12, 13, 18). Philips et al. (19) compared the YAG-holmium laser lithotripsy and basket-assisted open surgical removal approaches in the treatment of stones with an average size of $5.9 \mathrm{~mm}$. According to their results, laser surgery may be successfully carried out with minimal side effects. The length of laser surgery, the cost and the risk of damage to the salivary duct are disadvantages. We managed to fragment a $6 \mathrm{~mm}$ submandibular gland stone with a Holmium: YAG laser and retrieve it by a basket. We believed that using the laser for the treatment of large, non-floating stones can reduce the number of combined open surgery techniques with lithotomy in both the submandibular and the parotid glands.

The rate of stone removal with sialendoscopy varies between 70 and $90 \%(6,10,20)$. These success rates are related to the experi- 
ence of the surgeon and characteristics of the stone, such as size, location, number, shape, adherence to the duct and mobility (5, $6,16)$. Marchal et al. (21) reported a $97 \%$ success rate in removal of stones smaller than $3 \mathrm{~mm}$. Nahlieli et al. (22) and Iro et al. (23) also reported that stones of $<7 \mathrm{~mm}$ in the Wharton and the Stensen ducts could be removed with a success rate of more than $85 \%$. Stenting and corticosteroid irrigation are controversial subjects in preventing post-operative strictures and stenosis, and there are no prospective studies reported on these procedures $(5,14)$. Nahlieli $(3,8)$ applied stent treatment for four weeks and preoperative/postoperative systemic steroid treatment after endoscopic removal of stones and submandibular duct stricture dilatation. In our study, although the success rate was $100 \%$, this high rate was related to the sizes of the stones encountered in our study (all stones were smaller than $10 \mathrm{~mm}$ ), as well as the small sample size. As in the above-mentioned studies, we, too, irrigated the duct with steroids at the end of the surgery in all patients, but we only applied stents in patients with scars that were close to ostium.

The etiology and pathogenesis of non-specific chronic sialadenitis continue to remain unclear; but infection, autoimmune diseases and RAI therapy are often suspected (13). Chronic idiopathic sialadenitis cases are usually unilateral, 10 times more common than JRP and patients are likely to be women $(24,25)$. Sialendoscopy is performed in patients with severe complaints and recurrent swelling attacks (25). Compared to other imaging methods, sialendoscopy is the most sensitive method for diagnosis in chronic parotid sialadenitis (26). Compared to previous studies $(5,13,21)$, ductal scars in the parotid glands were found to be more common among our patients (in eight out of 12) who had chronic idiopathic sialadenitis. Sialendoscopy revealed stenosis and stricture in the distal part of the duct, an inflammatory ductal wall and low rate of stones in the order of frequency. We suggest that using intraoperative examination finding systems such as those described by Erkul and Gillespie (7) or by Marchal et al. (27) may guide the use of the exact treatment approach and the instruments in the management of ductal scars. We present our findings of ductal scars in Table 3. White-colored narrow ductal wall with no natural vascularization, ductal strictures, diffuse ductal stenosis and mucus plugs can be observed during sialendoscopy $(7,18,25)$. Mucus plugs are common, and they accompany most other findings. Removal of mucus plugs by irrigation is important to prevent new pathologies that may occur in the future $(7,25,28,29)$. We observed mucus plugs in all patients with ductal scars and in some patients with stones, and we removed these by abundant irrigation and ended the procedures with steroid irrigation. With this approach, we believe that we took preventive measures against future pathologies.

Treatment of scars may require instruments such as dilators, bougies, microdrills, balloons, endoscope tips and lasers $(7,25$, 30). If ductal wall edema and hyperemia are observed in patients with type 1 inflammatory stenosis, steroid irrigation is beneficial for the treatment. If the scar tissue is localized in the ostium or the main duct, inserting a salivary stent at the end of the procedure may be a good choice to prevent recurrences. Longer stric- tures, in particular, have a worse prognosis (7). In our study, we observed a pale ductal wall in six patients and an erythematous wall in three patients. Stenosis was examined with a high scar grade in the parotid gland, but both patients were successfully treated.

Kopec et al. (29) treated 27 parotid gland and 24 submandibular gland duct stenosis patients diagnosed by clinical examination, ultrasonography and sialendoscopy, and all stenosis cases were treated by only an endoscope or by various instruments. They applied intraductal $4 \mathrm{mg}$ dexamethasone and flexible stents for 14 to 21 days at the end of their sialendoscopy procedure. While $78 \%$ of the stenosis cases were isolated, $22 \%$ of the patients had stones. At the end of the mean follow-up of 24 months, a complete recovery was observed in the complaints of $78 \%$ of their patients. The authors reported that inflammatory stenosis responds well to treatment compared to stenosis with a duct wall covered with fibrous tissue (29). We also used an endoscope, baskets and balloons to treat ductal scars. Even though our success rate $(70 \%)$ was lower than what was reported by Kopec et al., our follow-up period was longer, and this may have been related to seeing more recurrences in a longer follow-up period. The success rate of stenosis treatment has been reported as $80 \%$ on the average in various studies $(5,7,11,13)$.

In a meta-analysis conducted in 2012, the success rate of sialendoscopy alone was found $86 \%$, while this success rate was reported as $93 \%$ with a combined minimally invasive surgery (5). In another systematic review which was conducted in 2015, the success rate of the treatment of obstructive salivary gland pathologies with interventional sialendoscopy was found only $76 \%$, and $91 \%$ with an additional surgical approach (6). In our study, our total success rate was $85 \%$, and in agreement with previous review studies $(5,6)$. Gillespie et al. (11) reported that patients with chronic obstructive sialadenitis who were treated by sialendoscopy with a mean follow-up of 17 months had a recovery rate of $89 \%$, and that the highest rate among the patients in their sample was achieved in stone patients. In agreement with the study by Atienza et al. (6), we had a higher success rate in stone patients than non-stone patients, but our follow-up period was longer than that study.

\section{Conclusion}

Sialendoscopy is a minimally invasive method for the diagnosis and treatment of sialolithiasis and ductal scars of the salivary glands after failure of conservative treatments in adults. It has both diagnostic and therapeutic properties with high success rates and low complication rates, and it can be performed under local or general anesthesia. Although the initial results are promising, stronger evidence is needed in the form of randomized, controlled trials with higher numbers of subjects and longterm follow-up in stone and non-stone obstructive disorders.

Ethics Committee Approval: Ethics committee approval was received for this study from the Ethics Committee of Haydarpaşa Numune Training and Research Hospital (Approval No.: HNEAH$\mathrm{KAEK} / 28.01 .2019-\mathrm{KK} / 1)$ 
Informed Consent: Written informed consent was obtained from the patients who participated in this study.

Peer-review: Externally peer-reviewed.

Author Contributions: Concept - E.E., E.C., A.G.; Design - E.E., E.C., A.G.; Supervision - E.E., E.C., A.G.; Resource - E.E.; Materials - E.E., E.C., A.G.; Data Collection and/or Processing - E.E., E.C., A.G.; Analysis and/or Interpretation - E.E., E.C., A.G.; Literature Search - E.E., E.C., A.G.; Writing - E.E., E.C., A.G.; Critical Reviews - E.E., E.C., A.G.

Conflict of Interest: The authors have no conflicts of interest to declare.

Financial Disclosure: The authors declared that this study has received no financial support.

\section{References}

1. Lydiatt DD, Bucher GS. The historical evolution of the understanding of the submandibular and sublingual salivary glands. Clin Anat 2012; 25: 2-11. [CrossRef]

2. Nahlieli O, Nakar LH, Nazarian Y, Turner MD. Sialoendoscopy: A new approach to salivary gland obstructive pathology. J Am Dent Assoc 2006; 137: 1394-400. [CrossRef]

3. Nahlieli O. Advanced sialoendoscopy techniques, rare findings, and complications. Otolaryngol Clin North Am 2009; 42: 105372. [CrossRef]

4. Geisthoff UW. Basic sialendoscopy techniques. Otolaryngol Clin North Am 2009; 42: 1029-52. [CrossRef]

5. Strychowsky JE, Sommer DD, Gupta MK, Cohen N, Nahlieli O. Sialendoscopy for the management of obstructive salivary gland disease: A systematic review and meta-analysis. Arch Otolaryngol Head Neck Surg 2012; 138: 541-7. [CrossRef]

6. Atienza G, López-Cedrún JL. Management of obstructive salivary disorders by sialendoscopy: a systematic review. Br J Oral Maxillofac Surg 2015; 53: 507-19. [CrossRef]

7. Erkul E, Gillespie MB. Sialendoscopy for non-stone disorders: The current evidence. Laryngoscope Investig Otolaryngol 2016; 1: 140-5. [CrossRef]

8. Nahlieli O. Complications of sialendoscopy: Personal experience, literature analysis, and suggestions. J Oral Maxillofac Surg 2015; 73: 75-80. [CrossRef]

9. Rasmussen ER, Lykke E, Wagner N, Nielsen T, Waersted S, Arndal H. The introduction of sialendoscopy has significantly contributed to a decreased number of excised salivary glands in Denmark. Eur Arch Otorhinolaryngol 2016; 273: 2223-30. [CrossRef]

10. Maresh A, Kutler DI, Kacker A. Sialoendoscopy in the diagnosis and management of obstructive sialadenitis. Laryngoscope 2011; 121: 495-500. [CrossRef]

11. Gillespie MB, O'Connell BP, Rawl JW, McLaughlin CW, Carroll WW, Nguyen SA. Clinical and quality-of-life outcomes following gland-preserving surgery for chronic sialadenitis. Laryngoscope 2015; 125: 1340-4. [CrossRef]

12. Serbetci E, Sengor GA. Sialendoscopy: Experience with the first 60 glands in Turkey and a literature review. Ann Otol Rhinol Laryngol 2010; 119: 155-64. [CrossRef]
13. Pace CG, Hwang KG, Papadaki M, Troulis MJ. Interventional sialoendoscopy for treatment of obstructive sialadenitis. J Oral Maxillofac Surg 2014; 72: 2157-66. [CrossRef]

14. Schwartz N, Hazkani I, Goshen S. Combined approach sialendoscopy for management of submandibular gland sialolithiasis. Am J Otolaryngol 2015; 36: 632-5. [CrossRef]

15. Gillespie MB, Intaphan J, Nguyen SA. Endoscopic-assisted management of chronic sialadenitis. Head Neck 2011; 33: 1346-51. [CrossRef]

16. Matsunobu T, Kurioka T, Miyagawa Y, Araki K, Tamura A, Niwa $\mathrm{K}$, et al. Minimally invasive surgery of sialolithiasis using sialendoscopy. Auris Nasus Larynx 2014; 41: 528-31. [CrossRef]

17. Capaccio P, Gaffuri M, Pignataro L. Sialendoscopy-assisted transfacial surgical removal of parotid stones. J Craniomaxillofac Surg 2014; 42: 1964-9. [Cross Ref]

18. Martins-Carvalho C, Plouin-Gaudon I, Quenin S, Lesniak J, Froehlich P, Marchal F, et al. Pediatric sialendoscopy: A 5-year experience at a single institution. Arch Otolaryngol Head Neck Surg 2010; 136: 33-6. [CrossRef]

19. Phillips J, Withrow K. Outcomes of Holmium laser-assisted lithotripsy with sialendoscopy in treatment of sialolithiasis. Otolaryngol Head Neck Surg 2014; 150: 962-7. [CrossRef]

20. Wu CB, Xue L, Zhang B, Sun NN, Zhou Q. Sialendoscopy-assisted treatment for chronic obstructive parotitis--our treatment strategy with 31 patients. J Oral Maxillofac Surg 2015; 73: 152431. [CrossRef]

21. Marchal F, Dulguerov P, Becker M, Barki G, Disant F, Lehmann W. Specificity of parotid sialendoscopy. Laryngoscope 2001; 111: 264-71. [CrossRef]

22. Nahlieli O, Shacham R, Bar T, Eliav E. Endoscopic mechanical retrieval of sialoliths. Oral Surg Oral Med Oral Pathol Oral Radiol Endod 2003; 95: 396-402. [CrossRef]

23. Iro H, Zenk J, Escudier MP, Nahlieli O, Capaccio P, Katz P, et al. Outcome of minimally invasive management of salivary calculi in 4,691 patients. Laryngoscope 2009; 119: 263-8. [CrossRef]

24. Iro H, Zenk J. Salivary gland diseases in children. GMS Curr Top Otorhinolaryngol Head Neck Surg 2014; 13: 1-30. [CrossRef]

25. Vashishta R, Gillespie MB. Salivary endoscopy for idiopathic chronic sialadenitis. Laryngoscope 2013; 123: 3016-20. [CrossRef]

26. Heineman TE, Kacker A, Kutler DI. Idiopathic chronic parotitis: Imaging findings and sialendoscopic response. ORL J Otorhinolaryngol Relat Spec 2015; 77: 302-9. [CrossRef]

27. Marchal F, Becker M, Dulguerov P, Lehmann W. Interventional sialendoscopy. Laryngoscope 2000; 110: 318-20. [CrossRef]

28. Nahlieli O, Nazarian Y. Sialadenitis following radioiodine therapy - a new diagnostic and treatment modality. Oral Dis 2006; 12 : 476-9. [CrossRef]

29. Kopeć T, Szyfter W, Wierzbicka M, Nealis J. Stenoses of the salivary ducts-sialendoscopy based diagnosis and treatment. Br J Oral Maxillofac Surg 2013; 51: e174-7. [CrossRef]

30. Koch M, Zenk J, Iro H. Algorithms for treatment of salivary gland obstructions. Otolaryngol Clin North Am 2009; 42: 1173-92. [Cross Ref] 